\title{
Gewekt vertrouwen in Europees perspectief : een rechtsvergelijkend onderzoek naar de rol van het vertrouwensbeginsel in het Nederlandse, Belgische, Duitse en Europese (belasting)recht
}

Citation for published version (APA):

Gorissen, N. H. A. (2008). Gewekt vertrouwen in Europees perspectief : een rechtsvergelijkend onderzoek naar de rol van het vertrouwensbeginsel in het Nederlandse, Belgische, Duitse en Europese (belasting)recht. [Doctoral Thesis, Maastricht University]. Universiteit Maastricht. https://doi.org/10.26481/dis.20081218ng

Document status and date:

Published: 01/01/2008

DOI:

10.26481/dis.20081218ng

Document Version:

Publisher's PDF, also known as Version of record

Please check the document version of this publication:

- A submitted manuscript is the version of the article upon submission and before peer-review. There can be important differences between the submitted version and the official published version of record. People interested in the research are advised to contact the author for the final version of the publication, or visit the $\mathrm{DOI}$ to the publisher's website.

- The final author version and the galley proof are versions of the publication after peer review.

- The final published version features the final layout of the paper including the volume, issue and page numbers.

Link to publication

\footnotetext{
General rights rights.

- You may freely distribute the URL identifying the publication in the public portal. please follow below link for the End User Agreement:

www.umlib.nl/taverne-license

Take down policy

If you believe that this document breaches copyright please contact us at:

repository@maastrichtuniversity.nl

providing details and we will investigate your claim.
}

Copyright and moral rights for the publications made accessible in the public portal are retained by the authors and/or other copyright owners and it is a condition of accessing publications that users recognise and abide by the legal requirements associated with these

- Users may download and print one copy of any publication from the public portal for the purpose of private study or research.

- You may not further distribute the material or use it for any profit-making activity or commercial gain

If the publication is distributed under the terms of Article $25 \mathrm{fa}$ of the Dutch Copyright Act, indicated by the "Taverne" license above,

Download date: 26 Apr. 2023 


\section{Samenvatting}

\section{GEWEKT VERTROUWEN IN EUROPEES PERSPECTIEF}

\section{HOOFDSTUK 1. INLEIDING}

Burgers en meer specifiek belastingplichtigen hebben vaak behoefte aan informatie van de overheid bij het nemen van beslissingen. Bestuursorganen zoals de Belastingdienst verstrekken op hun beurt op verschillende manieren informatie aan de burgers. Een stap verder gaat het sluiten van overeenkomsten met de overheid. De belanghebbende handelt doorgaans in overeenstemming met de verkregen informatie c.q. het gesloten compromis. Problemen doen zich voor als de Belastingdienst de belastingplichtige er vervolgens op wijst dat zijn handelswijze niet in overeenstemming met de wet c.q. het beleid is. Er dient dan een afweging gemaakt te worden tussen het vertrouwensbeginsel contra-legem en het legaliteitsbeginsel. Deze problemen doen zich niet alleen in Nederland voor, maar ook in andere landen. Ik beperk mij in dit onderzoek tot de landen Nederland, België en Duitsland en de jurisprudentie van het Hof van Justitie van de EG.

De formulering van de probleemstelling is uiteengevallen in vier subvragen:

1. In hoeverre dient vertrouwen op handelingen van de Nederlandse fiscale overheid te worden gehonoreerd mede in vergelijking met de rechtspraak op administratief gebied?

2. In hoeverre dient vertrouwen op handelingen van de Belgische of Duitse fiscale overheid te worden gehonoreerd?

3. Kan op basis van de in de lidstaten gebezigde rechterlijke criteria voor honorering van gewekt vertrouwen één Europees model worden gecreëerd?

4. Hoe past het Hof het vertrouwensbeginsel toe en sluit het door het Hof ontwikkelde vertrouwensbeginsel aan bij de fiscale modellen?

Bij de probleemstelling geformuleerde subvragen is in een aantal onderzoeksvragen geconcretiseerd:

a. Wat is de aard van de handelingen waaraan gerechtvaardigd vertrouwen kan worden ontleend?

b. Welke personen c.q. instellingen kunnen gerechtvaardigd vertrouwen wekken?

c. Wat is de rol van het dispositievereiste?

d. Onder welke omstandigheden kan gerechtvaardigd vertrouwen worden beëindigd? Met andere woorden, wanneer is sprake van een contra-indicatie?

\section{HOOFDSTUK 2. HET VERTROUWENSBEGINSEL IN NEDERLAND}

Voor de rol van het vertrouwensbeginsel in Nederland is een onderscheid gemaakt tussen het algemene bestuursrecht en het fiscale recht.

Het vertrouwensbeginsel is in Nederland een niet gecodificeerd algemeen beginsel van behoorlijk bestuur, waarbij de vraag speelt of het contra-legem mag worden toegepast. Geconcludeerd is dat de ene rechterlijke instantie soepeler omgaat met het honoreren van het vertrouwensbeginsel contra-legem dan de andere. Dit heeft onder andere te maken 
met het type zaken waarover de desbetreffende instanties oordelen. Verder is van belang of er derdebelangen c.q. het algemeen belang in het geding zijn. Dit is een reden waarom de ABRvS het vertrouwensbeginsel contra-legem meestal niet erkent. De CRvB is daarentegen wel genegen het vertrouwensbeginsel contra-legem te erkennen, maar hij behartigt dan ook doorgaans zaken die betrekking hebben op een individuele financiële relatie tussen de burger en het bestuursorgaan. Voor de Hoge Raad geldt in beginsel hetzelfde.

Tot 1970 heeft de Hoge Raad geoordeeld dat het vertrouwensbeginsel de wet in een concreet geval niet aan de kant kon zetten. De Hoge Raad ging ervan uit dat het legaliteitsbeginsel moest prevaleren boven het vertrouwensbeginsel. In 1970 oordeelt de Hoge Raad in het Voorburgse ziekenhuisarrest dat de belastingrechter slechts rekening mocht houden met een beroep op de algemene beginselen van behoorlijk bestuur in die gevallen waarin aan een overheidsorgaan bij de uitvoering van een wettelijk voorschrift een bepaalde beleidsvrijheid toekomt. Ook na het Voorburgse ziekenhuisarrest was de heersende leer daarom nog steeds dat als sprake was van een beleidsregel contra-legem, de rechter deze niet mocht toepassen. Pas in 1978, in de Doorbraakarresten, werd voor het eerst een beroep op het vertrouwensbeginsel contra-legem gehonoreerd.

De rechter dient ingeval een beroep wordt gedaan op gewekte verwachtingen contralegem steeds af te wegen of het vertrouwensbeginsel contra-legem dan wel het legaliteitsbeginsel, inhoudende strikte toepassing van de wet en voor de fiscaliteit verankerd in art. $104 \mathrm{Gw}$., voorrang heeft. Of een dergelijk beroep in het voordeel van het vertrouwensbeginsel uitvalt, is situatieafhankelijk.

De vertrouwenwekkende handeling (onderzoeksvraag a) is hierbij het belangrijkste. Er moet daarbij wel een onderscheid gemaakt worden tussen enerzijds informatie en anderzijds fiscale compromissen. Het verschil is gelegen in het moment waarop dit beroep plaatsvindt. Bij van de fiscus verkregen informatie is dit moment gelegen direct nadat de informatie is verkregen. Pas nadat een fiscaal compromis is gesloten, kan een geschil ontstaan ten aanzien van de interpretatie van de gemaakte afspraak. Ook nu is de vraag of de inhoud van het compromis van dien aard is dat bij de belastingplichtige gerechtvaardigd het vertrouwen is gewekt dat slechts één uitleg mogelijk is.

Onderzoeksvraag $\mathbf{b}$ handelt over de vraag of de persoon die het vertrouwen heeft gewekt bevoegd was. Zowel in het algemene bestuursrecht als in het fiscale recht is alleen sprake van een gerechtvaardigd gewekt vertrouwen als de handeling door een bevoegde persoon is verricht dan wel aan een bevoegde persoon kan worden toegerekend.

Het dispositievereiste staat in onderzoeksvraag c centraal. Heeft degene die schade lijdt doordat door de overheid gewekt vertrouwen alsnog wordt beschaamd, meer recht op bescherming dan degene bij wie wél sprake is van een teleurstelling, maar niet van echte schade? Bij onderzoeksvraag c. zijn de verschillen tussen het algemene bestuursrecht en het fiscale recht het duidelijkste naar voren gekomen, aangezien de rol van het dispositievereiste in bepaalde gevallen in het fiscale recht van ondergeschikt belang is. In het bestuursrecht vormt het dispositievereiste echter meer een voorwaarde waar rekening mee wordt gehouden bij het al dan niet honoreren van een beroep op het vertrouwensbeginsel.

Ten slotte is in onderzoeksvraag $\mathbf{d}$ onderzocht of en binnen welke termijn gerechtvaardigd vertrouwen kan worden beëindigd. Belangrijke voorbeelden van een dergelijke contra-indicatie zijn: belastingplichtige heeft een onjuiste of onvolledige voorstelling van zaken gegeven; er is sprake van een kennelijke vergissing van de fiscus; het beleid of de omstandigheden wijzigen.

\section{HOOFDSTUK 3. GEWEKT VERTROUWEN IN BELGIË}

In België is het vertrouwensbeginsel ook een algemeen beginsel van behoorlijk bestuur, maar het is ontstaan uit de zorgvuldigheids- en voorzichtigheidsplicht die de overheid jegens haar burgers in acht moet nemen. Die zorgvuldigheidsplicht vloeit voort uit het civiele recht (art. 1382 en 1383 BW). Echter vanaf het arrest van het Hof van Cassatie van 27 maart 1992 wordt aangenomen dat de grondslag van het vertrouwensbeginsel in het 
principe van de rechtsstaat ligt. Sinds genoemd arrest is de klassieke leer (welke het vertrouwensbeginsel contra-legem niet erkende) verfijnd. Voor een geslaagd beroep op het vertrouwensbeginsel contra-legem moet volgens de jurisprudentie nu in ieder geval sprake zijn van een vaste gedrags- of beleidsregel en moeten de verwachtingen gerechtvaardigd zijn, maar hoe dan ook er zal altijd een afweging van belangen moeten plaatsvinden tussen het legaliteitsbeginsel (art. 170 en $172 \mathrm{GW}$ ) en het vertrouwensbeginsel. Het is dus van de concrete omstandigheden van het geval afhankelijk of een beroep op gewekt vertrouwen slaagt. Deze concrete omstandigheden worden met name gevormd door de aard van de handeling. Daarnaast speelt mee of de handeling door een bevoegd persoon is verricht en of de belastingplichtige benadeeld wordt als zijn verwachtingen niet gehonoreerd worden. Ten slotte kan een contra-indicatie ervoor zorgen dat gewekt vertrouwen niet langer ingewilligd wordt.

\section{HOOFDSTUK 4. GEWEKT VERTROUWEN IN DUITSLAND}

In Duitsland wordt in tegenstelling tot Nederland en België niet over één begrip 'vertrouwensbeginsel' gesproken, maar over zowel het beginsel van 'Treu und Glauben' als het 'Vertrauensschutzprinzip'. Daarnaast kent Duitsland geen contra-legem toepassing zoals die in Nederland en België wordt toegepast, omdat zowel het 'Vertrauensschutzprinzip' als het legaliteitsbeginsel uit het rechtsstaatbeginsel van art. 20 Abs. 3 GG. afgeleid worden. Echter ook in Duitsland zal een normafweging tussen het legaliteitsbeginsel en het vertrouwensbeginsel moeten plaatsvinden en blijken de concrete omstandigheden van de casus doorslaggevend te zijn voor de beantwoording van de vraag of gewekte verwachtingen gehonoreerd worden c.q. de handeling bindend is voor de fiscus.

Voor Duitsland is de aard van de gedraging die vertrouwen kan wekken, eveneens het belangrijkste als het gaat om de beslissing of een handeling bindend is voor de fiscus. Voor het uiteindelijke oordeel of de handeling bindend is, speelt echter ook de persoon die het vertrouwen gewekt heeft, het dispositievereiste en de rol van de contra-indicaties mee.

\section{HOOFDSTUK 5. GEWEKT VERTROUWEN OP EUROPEES NIVEAU}

Het vertrouwensbeginsel slaagt in Europeesrechtelijke casus niet zo snel, omdat in beginsel een contra-legem toepassing is uitgesloten en een hoge mate van professionaliteit van de marktdeelnemer wordt verwacht.

Een, niet altijd scherp te stellen, onderscheid moet worden gemaakt tussen de directe toepassing van het EG-recht door nationale uitvoeringsorganen en de indirecte toepassing ervan. Bij de directe toepassing geldt het communautaire vertrouwensbeginsel. Dit houdt in dat een contra-legem toepassing uitgesloten is. Let wel, in het CDW is het vertrouwensbeginsel met betrekking tot navordering gecodificeerd. Gesteld is dat het gecodificeerde vertrouwensbeginsel en de BTI in feite toepassingen van het vertrouwensbeginsel contralegem zijn, maar doordat ze gecodificeerd zijn, de facto niet gezegd kan worden dat het om contra-legem handelen gaat.

Bij de indirecte toepassing mogen de regels van het nationale recht, waartoe het nationale vertrouwensbeginsel behoort, worden toegepast, omdat het Europese recht geen specifieke regel geeft. Wel geldt de beperking van de vereisten van gelijkwaardigheid (de regels mogen niet ongunstiger zijn dan die welke voor soortgelijke vorderingen krachtens nationaal recht gelden) en doeltreffendheid (de uitoefening van de door de communautaire rechtsorde verleende rechten mogen in de praktijk niet onmogelijk of uiterst moeilijk gemaakt worden).

Binnen de indirecte toepassing is nog een onderscheid gemaakt tussen enerzijds terugvordering van (onrechtmatige) communautaire gelden en anderzijds terugvordering van (onrechtmatige) nationale steun oftewel staatssteun. Als het om staatssteun gaat, is de eis van doeltreffendheid strenger dan wanneer het gaat om communautaire steun. Bij staatssteun heeft een beroep op gerechtvaardigd vertrouwen eigenlijk in beginsel alleen kans van slagen als de steun door middel van art. 88 EG-Verdrag is toegekend. 


\section{HOOFDSTUK 6. RECHTSVERGELIJKING EN AANBEVELING}

Rechtsvergelijking Nederland, België en Duitsland

Uit het rechtsvergelijkend onderzoek tussen de drie lidstaten, Nederland, België en Duitsland is gebleken dat de vraag of er één Europees model voor gewekt vertrouwen bestaat, negatief moet worden beantwoord. De reden hiervoor is dat iedere onderzochte lidstaat zijn eigen systeem met eigen vereisten heeft. Wel bestaat een gemeenschappelijke basis. Geconcludeerd is dat Nederland, België en Duitsland alle drie tot op zekere hoogte een contra-legem toepassing van het vertrouwensbeginsel accepteren. Ze doen dus alle aan toetsing aan het vertrouwensbeginsel. Verder blijkt dat in alle onderzochte landen de aard van de handeling de beste indicatie geeft of een beroep op gewekt vertrouwen gehonoreerd wordt. Daarnaast hebben de drie lidstaten gemeen dat het steeds situatieafhankelijk is of vertrouwen in een bepaalde casus daadwerkelijk gehonoreerd wordt. Bij de behandeling van alle drie de lidstaten spelen naast de vertrouwenwekkende handeling steeds de volgende factoren een rol:

- de persoon die het vertrouwen heeft gewekt;

- het dispositievereiste en

- de aanwezigheid van bepaalde contra-indicaties, zoals het te kwader trouw zijn van de belastingplichtige of een verandering van omstandigheden.

De terminologie met betrekking tot de vertrouwenwekkende handelingen komt in de lidstaten niet geheel overeen en vaak heeft iedere lidstaat per handeling zijn eigen (jurisprudentiële) vereisten. Doordat de uitwerking van de basisgedachte in iedere lidstaat anders verloopt, is beschreven dat geen er Europees model met betrekking tot gewekt vertrouwen bestaat. Het gevolg is dat het Hof hier dus ook niet bij kan aansluiten en zijn eigen weg moet zoeken. Echter er valt mijns inziens wel de onderstaande vaste lijn te signaleren bij de kwalificatie van de verschillende vertrouwenwekkende handelingen in de drie onderzochte lidstaten:

Voor belastingbeschikkingen geldt dat zij in beginsel vertrouwen wekken, maar dat wel iedere beschikking op zichzelf staat en dat daarom doorgaans niet vertrouwd mag worden dat in de toekomst dezelfde beschikking gegeven zal worden als in het verleden. Rekening moet nog worden gehouden met de regels omtrent het opzeggen, intrekken of veranderen van beschikkingen.

Voor beleidsregels geldt grofweg dat extern werkende beleidsregels vertrouwen kunnen wekken. Het mag dus niet een intern stuk betreffen dat louter een werkinstructie voor de ambtenaren is. Tevens moeten de beleidsregels bekend zijn gemaakt, willen zij gerechtvaardigd vertrouwen kunnen wekken.

Bij toezeggingen zijn de verschillen tussen de lidstaten groter. Duitsland kent een wettelijke regeling voor verschillende vormen van toezeggingen (§ 204-207 AO, $\S 42^{\mathrm{e}} \mathrm{EStG}, 2 \mathrm{ZK}$ en § 89 Abs. $2 \mathrm{AO}$ ) en daarnaast nog de 'tatsächliche Verständigung' die als bindende verklaring wordt gezien en door de heersende mening in de literatuur als 'öffentlich-rechtlicher Vertrag' gekwalificeerd wordt. Nederland maakt doorgaans strikt onderscheid tussen inlichtingen en toezeggingen, maar vervangt de term toezeggingen recent steeds meer door de term bewuste standpuntbepalingen. België maakt tenslotte niet zo'n strikt onderscheid tussen inlichtingen en toezeggingen. Een gezamenlijke noemer is echter dat in alle lidstaten een concrete toezegging van het bevoegde orgaan, zonder de aanwezigheid van contra-indicaties vertrouwen wekt.

$\mathrm{Bij}$ inlichtingen is de gezamenlijke noemer te vinden in het feit dat zij doorgaans geen vertrouwen wekken. Verder is er nog de algemene voorlichting: ook deze wekt in beginsel geen vertrouwen. Inlichtingen en algemene voorlichting worden in de drie lidstaten in principe gezien als algemene informatie.

Als laatste bestaat een soort restcategorie die ik vaak de overige vertrouwenwekkende handelingen heb genoemd. Hieronder valt vertrouwen door een jarenlang gevolgde gedragslijn, vertrouwen door een boekenonderzoek, of vertrouwen door gedogen dan wel stilzitten van de fiscus. In Nederland is hierover een ruime hoeveelheid jurisprudentie 
aanwezig. In België bestaat deze categorie eveneens, al zijn de jurisprudentiële ontwikkelingen hier nog niet zover uitgekristalliseerd als in Nederland. In Duitsland bestaat de categorie 'konkludentes Verhalten', waarbij het gaat om een wijze van gedrag van de fiscus, waaruit de belastingplichtige slechts één conclusie kan trekken.

Naast de hier behandelde handelingen zijn er nog enkele handelingen specifiek voor een betreffende lidstaat, zij zijn dan alleen bij de betreffende lidstaat behandeld.

Een belangrijke categorie vertrouwenwekkende handelingen die ik apart behandeld heb, zijn de fiscale compromissen, de vaststellingsovereenkomsten, de overeenkomsten met de overheid, de rulings en de APA's. Overeenkomsten wekken in beginsel vertrouwen. De vraag is met name of het vertrouwen is gewekt op de manier waarop de belastingplichtige de overeenkomst geïnterpreteerd heeft. In alle drie de lidstaten zijn hiervoor de privaatrechtelijke regels van de uitleg van belang. Echter, de vormgeving en de bereidheid van de fiscus om aan een bepaald type overeenkomst medewerking te verlenen, kunnen per onderzochte lidstaat duidelijk verschillen. Ik vind dat in Nederland de grootste bereidheid van de fiscus bestaat om een fiscaal compromis of een APA met de belastingplichtige af te sluiten. Tevens wordt in Nederland minder moeilijk gedaan over rechtsvragen die onderdeel uitmaken van een overeenkomst. In België en Duitsland wordt volgens mij strikter de hand gehouden aan de regel dat een overeenkomst in principe alleen om feitenkwesties mag gaan en niet (louter) om rechtsvragen. Hierbij past wel de kanttekening dat in Nederland na de 'Vinkenslagaffaire' iets meer terughoudendheid wordt betracht bij het aangaan van overeenkomsten.

Een onderscheid tussen Duitsland aan de ene kant en Nederland en België aan de andere kant, zit in het feit dat in Duitsland voor de aanvraag van een 'verbindliche Auskunft nach $\S 89$ Abs. 2 AO' en een APA uit § 178a AO betaald moet worden. Terwijl in Nederland en België, mijns inziens terecht, voor geen enkele vorm van informatie betaald hoeft te worden.

Een belangrijk verschil tussen de drie lidstaten vind ik verder nog dat in Duitsland een uitgebreide wettelijke regeling bestaat met betrekking tot verschillende 'Zusagen' en 'verbindliche Auskünfte', terwijl Nederland en België daarentegen geen enkele handeling op een dergelijke manier in een wettelijke regeling vastgelegd hebben. De wettelijke regeling leidt echter niet tot een ander resultaat.

Rechtsvergelijking lidstaten met het Hof van Justitie van de EG

Bij een rechtsvergelijking tussen de drie onderzochte lidstaten aan de ene kant en het communautaire niveau aan de andere kant valt op dat zij gemeen hebben dat het vertrouwensbeginsel situatieafhankelijk is en dat de vertrouwenwekkende handeling de beste indicatie geeft of een beroep op het vertrouwensbeginsel gehonoreerd wordt. Op communautair niveau zal bijvoorbeeld ook sprake moeten zijn van precieze toezeggingen, wil een beroep op het vertrouwensbeginsel slagen. Verder zal een beroep op het vertrouwensbeginsel slagen als het gaat om besluiten, verordeningen, mededelingen, richtlijnen en in uitzonderlijke gevallen stilzitten. De andere factoren zoals de (bevoegde) persoon die het vertrouwen heeft gewekt, het dispositievereiste (met name het schadeaspect) en de eventuele contra-indicaties (zoals wijziging van omstandigheden en het niet te goeder trouw zijn van de marktdeelnemer) spelen net als in de drie behandelde lidstaten daarnaast een soort 'corrigerende rol'.

Ondanks deze overeenkomsten, ben ik van mening dat het vertrouwensbeginsel op communautair niveau een in belangrijke mate eigen karakter heeft. De reden hiervoor zijn de significante verschillen (in beginsel geen contra-legem toepassing geaccepteerd en de verwachting van een hoge mate van deskundigheid van de marktdeelnemer) in de toepassing van het vertrouwensbeginsel door het Hof.

Conclusie en aanbeveling

Geconcludeerd is dat zowel in het Nederlandse, Belgische en Duitse als in het communautaire rechtsbestel de mening heerst dat het vertrouwensbeginsel een belangrijk rechtsbe- 
ginsel is en dat het de rechtsbescherming ten goede komt als gerechtvaardigde verwachtingen gehonoreerd worden. Ieder land heeft weliswaar zijn eigen systeem, waardoor niet van één Europees model gesproken kan worden, maar het vertrouwensbeginsel wordt terecht overal van belang geacht.

Ik ben echter van mening dat het vertrouwensbeginsel in het Nederlandse fiscale recht in vergelijking met het vertrouwensbeginsel in het Nederlandse algemene bestuursrecht, het Belgische en Duitse fiscale recht en de rechtspraak van het Hof, de meeste rechtsbescherming biedt. Wat dat betreft kunnen deze rechtssystemen dus nog wat leren van de rechtsbescherming met betrekking tot gerechtvaardigde verwachtingen die in het Nederlandse fiscale systeem geboden wordt en verdient het aanbeveling dat de overige onderzochte systemen zich wat meer in de richting van het model van gewekt vertrouwen in de Nederlandse fiscaliteit bewegen.

Wat betreft de drie lidstaten heb ik beschreven dat Nederland het land is dat mijns inziens het verst gaat in de acceptatie van gewekt vertrouwen door contra-legem handelingen. België lijkt hierin Nederland steeds meer te gaan volgen, alleen voorlopig wordt daar helaas nog niet zo uitgesproken een contra-legem handeling geaccepteerd. De rechtsbescherming in Duitsland gaat bij bepaalde contra-legem handelingen ook minder ver dan in Nederland, maar een voordeel van het Duitse systeem is wel dat er een wettelijk kader bestaat dat voor de nodige duidelijkheid zorgt.

Wat betreft het Hof is beschreven dat het een contra-legem toepassing van het communautaire vertrouwensbeginsel in beginsel uitsluit. Ik vind echter dat het Hof minder strikt de hand zou moeten houden aan het verbod op het toepassen van het vertrouwensbeginsel contra-legem, in het geval dat het vertrouwen door bijvoorbeeld een concrete toezegging van een gemeenschapsinstelling zelf is gewekt en er geen contra-indicaties aanwezig zijn. Als suggestie heb ik opgemerkt dat de constructie van het codificeren van het vertrouwensbeginsel in de mensenrechtenverdragen of het Handvest wellicht een opening kan bieden voor het Hof om de teugels wat betreft contra-legem wat te laten vieren. Ik heb hiervoor ook een tekstvoorstel opgenomen.

Op communautair niveau moet echter rekening worden gehouden met het feit dat niet alleen het communautaire vertrouwensbeginsel, maar ook het nationale vertrouwensbeginsel een rol speelt. Als namelijk sprake is van indirecte toepassing van het Europese recht, moeten de lidstaten hun nationale vertrouwensbeginsel met inachtneming van de eisen van gelijkwaardigheid en doeltreffendheid toepassen. Voor landen als Nederland en Duitsland heb ik beschreven dat het nationale vertrouwensbeginsel doorgaans meer rechtsbescherming biedt dan op Europees niveau wordt toegestaan. Deze verdergaande bescherming die in de onderzochte lidstaten Nederland en Duitsland en in mindere mate in België van toepassing is, verdient volgens mij navolging.

Voor landen die geen of slechts een beperkte bescherming door het vertrouwensbeginsel kennen, heb ik de aanbeveling gedaan om de regels van het te codificeren communautaire vertrouwensbeginsel, met inachtneming van de eisen van gelijkwaardigheid en doeltreffendheid als minimumstandaard te hanteren. Daarbij moet dan wel erop worden gelet, dat bij de toepassing van het nationale vertrouwensbeginsel in beginsel het vertrouwen niet door een instelling van de Unie, maar door de nationale instantie is gewekt.

Ten slotte ben ik van mening dat door het communautaire vertrouwensbeginsel te codificeren er niet alleen een mogelijkheid ontstaat voor het Hof om, zonder van zijn strikte anti contra-legem beleid af te wijken, gewekte verwachtingen van de gemeenschapsinstelling te honoreren, maar zorgt het gecodificeerde vertrouwensbeginsel er ook voor dat de rechtsbescherming in alle lidstaten van de Europese Unie een acceptabele minimumstandaard heeft. 